\title{
Peculiarities of hydration processes of cements containing natural zeolite
}

\author{
Kh. Sobol ${ }^{1}$, T. Markiv ${ }^{2}$, V. Terlyha ${ }^{3}$, W. Franus ${ }^{4}$ \\ ${ }^{1,2,3}$ Department of BuildingProduction,Institute of Building and Environmental Engineering, \\ National UniversityLviv Polytechnic, Lviv,Ukraine, e-mail:khrystyna.s.sobol@lpnu.ua, \\ taras.y.markiv@lpnu.ua,volodymyr.s.terlyha@lpnu.ua \\ ${ }^{4}$ Department of Geotechnics, Lublin University of Technology, Lublin, Poland, \\ e-mail:w.franus@pollub.pl
}

\begin{abstract}
In this study, properties and peculiarities of hydration processes as well as paste microstructure of blended cements containing $10 \%$ by weight of natural zeolite were investigated. Free calcium hydroxide content, crystalline hydration products and microstructural architecture of hydrated cement pastes were examined by physical and chemical methods. It was found that the addition of natural zeolite provides formation of an extra amount of fine crystalline ettringite and tobermorite-like calcium hydrosilicates of CSH (B) type in the mineral non-clinker part of Portland cement resulting in strength synthesis of cement stone with high performance properties.
\end{abstract}

Keywords: blended cement, natural zeolite, hydration, microstructure, pozzolanic activity, plasticizer.

\section{Introduction}

The analysis of modern world progress of cement industry trends evidences the increase of producing of less power-consuming Portland cement, that contains mineral additives. One of the most widespread methods of obtaining this kind of cement is mixing of ordinary Portland cement with the additives characterized by different types of activity (hydraulic and pozzolanic). The use of such additives helps increase the durability of cements, particularly in aggressive environment, and decrease probability of alkaline corrosion $[1-4]$.

Among well-known mineral additives with pozzolanic properties the industrial wastes (fuel slags, ashes) and natural pozzolana (pumice, diatomite, and zeolite) can be distinguished. Zeolites are of great interest due to their accessibility in large amont beds and, despite their crystalline structure, wonderful pozzolanic activity $[5,6]$.

Chemical composition of zeolite-containing rocks is not stable which can be explained by both the presence of impurities and hydrochemical conditions of their formation. According to Franus [7], zeolites are a group of alumosilicates of crystalline skeleton which includes the cavities, united by open channels - windows, that are of great importance for the processes related to adsorption and mass transfer. That is why zeolites are often called "porous crystals" or "molecular sieves" [8]. The research [9-11] shows that some natural zeolites, depending on the size of pores and channels, can be used for internal curing of hydraulic binder. Sobol et al. [12] believe that one of zeolite features is that it, in addition to the active binding of lime, it absorbs $\mathrm{SO}_{3}$ even more actively due to alumina (contained in the zeolite) - its activity (easy release from alumosilicate structure), based on dispersion and crystallinity. 
Wagner [13] supposes that ions of alkaline metals in zeolites can be replaced by calcium, followed by zeolites destruction. Released silica and alumina bind calcium hydroxide by forming hydrosilicates and possibly calcium hydroaluminate. According to Sanytsky et al. [14], modification of cement systems by chemical admixtures leads to direct impact on physical and mechanical properties of the cement stone. At the same time, the processes of structure formation of modified by chemical admixtures Portland cement mixed with the addition of zeolite were not sufficiently examined.

Therefore the aim of this work is to study the phase composition and microstructure of modified Portland cement containing natural zeolite.

\section{Materials and methods of research}

Zeolitic tuff from the Sokyrnytsia deposits, the Transcarpathian region of Ukraine, characterized by a high clinoptilolite content, and Portland cement PC I-500 were used in this study. The chemical composition of Portland cement and zeolite is shown in Table 1.

Table 1. Chemical composition and mineralogical compounds of Portland cement and natural zeolite

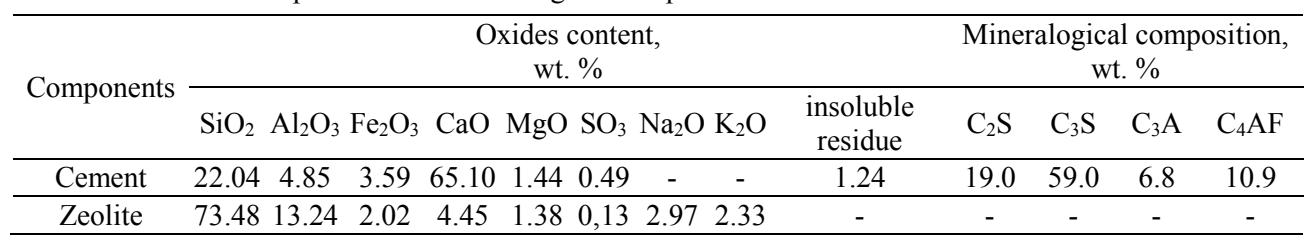

The physical and mechanical properties of Portland cement are presented in Table 2.

Table 2. Physical and mechanical properties of Portland cement

\begin{tabular}{ccccccc}
\hline \multirow{2}{*}{$\begin{array}{c}\text { Specific surface, } \\
\mathrm{m}^{2} / \mathrm{kg}\end{array}$} & \multirow{2}{*}{$\begin{array}{c}\text { Residue on sieve 008, } \\
\%\end{array}$} & \multirow{2}{*}{$\begin{array}{c}\text { Water demand, } \\
\%\end{array}$} & \multicolumn{2}{c}{$\begin{array}{c}\text { Setting time, } \\
\text { min }\end{array}$} & \multicolumn{2}{c}{$\begin{array}{c}\text { Compressive strength, } \\
\text { MPa }\end{array}$} \\
\cline { 4 - 7 } & & & initial & final & 2 days & 28 days \\
\hline 431 & 0.2 & 29.5 & 160 & 210 & 25.4 & 52.1 \\
\hline
\end{tabular}

The commercially available plasticizer on the basis of the water salt solution of aliphatic amines and detergents with a specific gravity of 1.16 was used in this study.

The mineral composition of zeolitic tuff was determined by means of a powder X-ray diffraction method, using a Panalytical X'pert APD diffractometer (with a PW 3020 goniometer), a $\mathrm{Cu}$ lamp and a graphite monochromator. The analysis was performed in the angle range of 5-65 20. The Philips X'Pert Highscore software was used to process the diffraction data. The identification of mineral phases was based on the PDF-2 release 2010 database formalized by the ICDD.

Thermal analysis of samples was carried out using a derivatograph Q-1500D (system F.Paulic, J.Paulic, L.Erdey). Registration of analytical signal of mass loss and thermal effects was carried out using a computer.

The sample was analyzed in a dynamic mode of heating rate of $10^{\circ} \mathrm{C} / \mathrm{min}$ in air. The weight of the sample was $200 \mathrm{mg}$. Aluminum oxide was used as the reference substance. The samples were heated up to $1000{ }^{\circ} \mathrm{C}$.

The morphology of clinoptilolite and chemical composition as regards main mineral components of the investigated materials was examined by scanning electron microscope SEM FEI Quanta 250 FEG, equipped with EDS. 


\section{Results and discussion}

Research of hydration processes of cement which contains zeolite and chemical modifiers, and the studies of genesis of its microstructure are very important, as they open a way to scientific forecasting of product properties, in particular their durability.

Investigations of Portland cement (paste 1:0, samples-cubes $2 \times 2 \times 2 \mathrm{~cm}$ ) compositions the results of which are given in Table. 3 showed that the replacement of $10 \mathrm{wt} . \%$ of Portland cement by zeolite leads to an increase by $6 \%$ of water demand (Fig. 1). This is attributed to the microstructure of zeolite, which is represented by a large number of pores connected by a huge grid of channels. The addition of water reducing plasticizers can diminish water demand of Portland cement by $10 \%$.

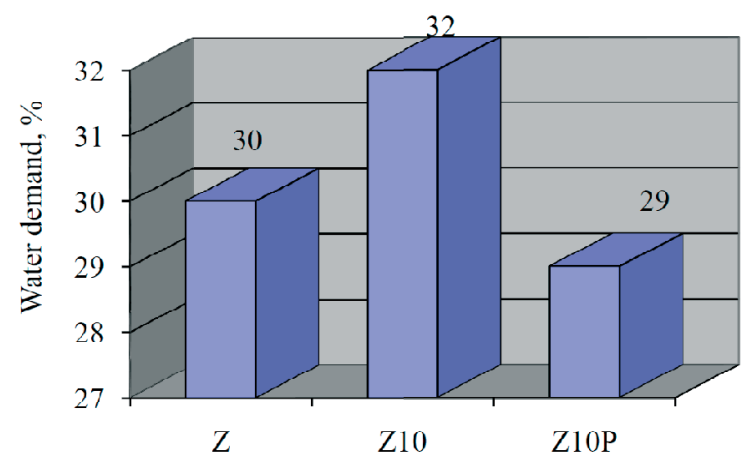

Fig. 1. Water demand for cement pastes

The initial and final setting time of the cements containing natural zeolite was shorter than that of reference Portland cement without zeolite. Although replacing some quantity of Portland cement by mineral additives usually results in a delay in setting time of cementitious system due to a lower amount of clinker in the binder. The opposite phenomenon is observed when zeolite is added due to a rapid decrease in consistency of the blended cement pastes, which is caused by rapid absorption of water by zeolitic tuff particles just after preparation of cement pastes of normal consistency. This is evidenced shorter initial setting time in comparison with the final setting time shortening and makes 15 and 30 min respectively, as the process of water absorption by zeolite grains gets slower over time because the zeolite particles become almost saturated.

It is stated [14] that the use of plasticizers is one of the most versatile, available and flexible methods of cements property regulation. Plasticizing action mechanism consists primarily in the formation of hydrophilic adsorption film on the entire surface of the cement grains and erasing new formations. This adsorption cover firmly holds on the surface a thick layer of water bound with the surface by molecular forces as well as part of water held in the adsorbed gel-like layer of surface active substances. Such stabilizing layers (adsorption hydration shell on a solid surface) perform two functions: firstly, they eliminate traction between the particles, providing hydrodynamic lubrication, namely reduce the friction between them, which is the main cause of increased fluidity of paste; secondly, the hydrophilic adsorption layers inhibit heterogeneous processes of cement hydration and hydrolysis in the initial period because of the appearance of a significant diffusion resistance in the transition layers. The addition of zeolite together with the plasticizer results in initial and final setting time delaying by 15 and 35 min respectively compared to Portland cement without additives (Fig. 2). 


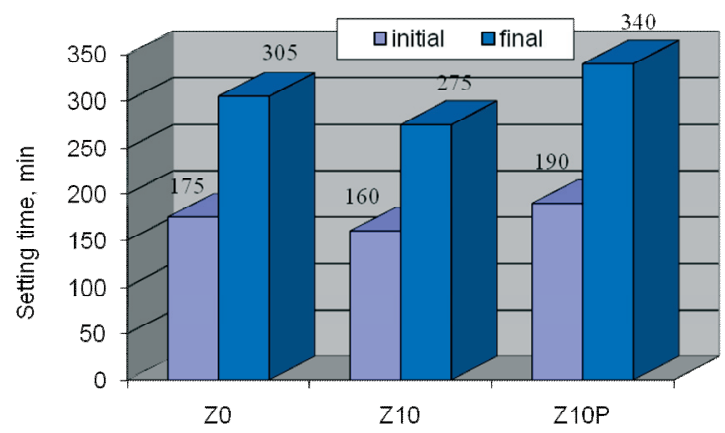

Fig. 2. Setting time of cement pastes

The active structure formation role of zeolite and chemical admixtures is confirmed by the cement stone strength determination results (Table 3). Thus, the compressive strength of Portland cement incorporating zeolite and both zeolite and plasticizer at an early age, has been reduced by $10-20 \%$. However, kinetics of strength development of Portland cement containing zeolite increases with time of hardening and after 28 days of curing the strength of such Portland cements has not yield that of Portland cement without additives.

Table 3. Compressive strength of the zeolite containing cement

\begin{tabular}{ccccccc}
\hline Mixture & \multicolumn{2}{c}{ Cement composition, wt.\% } & \multicolumn{3}{c}{ Compressive strength (MPa) } \\
\cline { 2 - 7 } identification & Portlandcement & Zeolite & Plasticizer & 3 days & 7 days & 28 days \\
\hline Z0 & 100 & 0 & 0 & 54.8 & 56.0 & 75.7 \\
\hline Z10 & 90 & 10 & 0 & 50.9 & 56.4 & 75.0 \\
\hline Z10P & 90 & 10 & 0.42 & 48.8 & 54.8 & 75.5 \\
\hline
\end{tabular}

The peculiarities of hydration processes of cement incorporating mineral additives and chemical admixtures were studied by the method of physical and chemical analysis.

The diffractogram analysis has shown the evidence of active processes of hardening and formation of basic hydrated phases (Fig. 3). On the diffractograms of the cement hydrated without additives alongside with alite and belite phase lines $(\mathrm{d} / \mathrm{n}=0.277 ; 0.273 \mathrm{~nm})$ the lines of calcium hydroxide $(\mathrm{d} / \mathrm{n}=0.263 ; 0.493 \mathrm{~nm})$, and those of ettringite of small intensity are observed after 28 days of hardening. Partial replacement of cement by zeolite leads to a reduction of $\mathrm{Ca}(\mathrm{OH})_{2}$ lines and growth of calcium hydrosulfoaluminate lines. Interaction of active $\mathrm{Al}_{2} \mathrm{O}_{3}$ with calcium hydroxide in the presence of gypsum promotes the formation of additional quantities of ettringite $(\mathrm{d} / \mathrm{n}=0.973 ; 0.561 \mathrm{~nm})$. It should be noted that the phase composition of hydration products virtually does not change after the extra addition of plasticizing chemical admixtures.

The effectiveness of zeolite action in the hydration processes of cement compositions is confirmed by the research carried out using thermal analysis (Fig. 4). On the DTA curves of the Portland cement hydrated for 28 days endothermic peaks has been fixed at 100, 500 and $720^{\circ} \mathrm{C}$. The first peak evidences water release from calcium hydrosilicates and hydrosulfoaluminate, the second one - decomposition of calcium hydroxide and the third peak corresponds to decomposition of calcium hydrocarboaluminate. Reduction of endothermic peak at $500^{\circ} \mathrm{C}$ of the zeolite containing sample shows the decrease of the amount of $\mathrm{Ca}(\mathrm{OH})_{2}$ from 15.3 (for Portland cement without additives) to $12.5 \%$ due to its reaction with the pozzolanic mineral additive that is confirmed by X-ray diffraction analysis. According to the thermogravimetry data, the total weight loss for pure cement (without additives) is $27.6 \mathrm{wt} . \%$ and with the addition of zeolite $10 \mathrm{wt} . \%-24.1 \%$. 


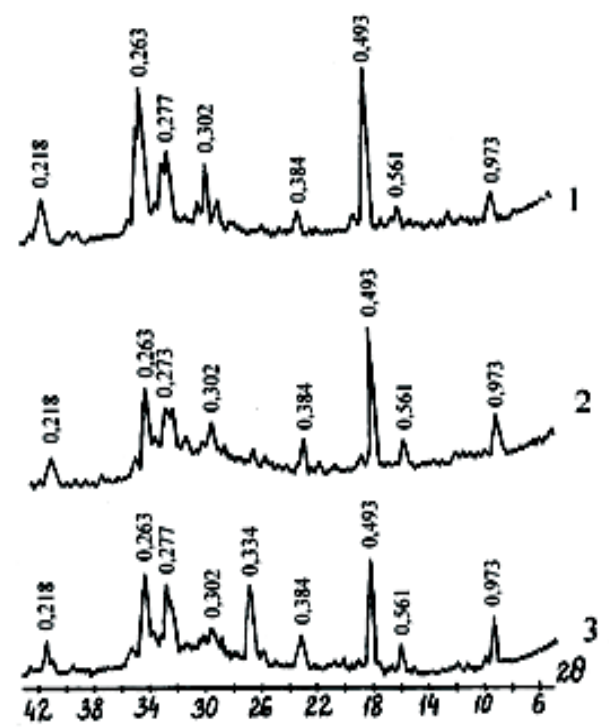

Fig. 3. XRD patterns of hardened cement stone after 28 days: 1) without additives; 2) with $10 \mathrm{wt} . \%$ of zeolite; 3) with $10 \mathrm{wt} . \%$ of zeolite and $0.42 \mathrm{wt} . \%$ of plasticizer

The electron microscopy method complements the data on the structure formation of cement stone. Microstructure analysis of the cement stone without additives after 28 days of hardening (Fig. 5) shows the intensive progress of the hydration processes. In the bulk microstructure is presented by a large number of hydrated formations. Some crystals have a shape of fine needle-like or plate-like formations, and thus contribute to the stepped growth of some layers of hydrated formations. In some places, tight hexagonal plates composed of calcium hydroxide have been changed (Fig. 5a), which is confirmed by the microprobe analysis (Fig. 5b).

a)

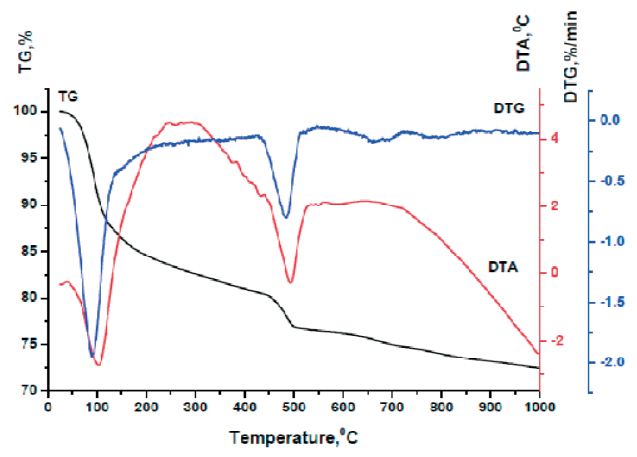

b)

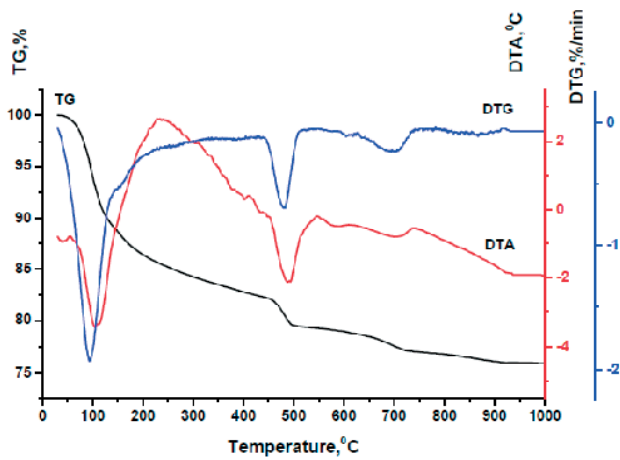

Fig. 4. DTA diagrams of hardened cement pastes after 28 days: a) without zeolite, b) with $10 \mathrm{wt} . \%$ of zeolite

Microstructure of Portland cement with the zeolite additive after 28 days of hardening is characterized by increasing homogeneity and formation of dense submicroscopic clusters of hydrosilicates and calcium hydrosulfoaluminates (Fig. 6). In some places crystalline blocks of lamellar crystals of Portlandite are observed. 
a)

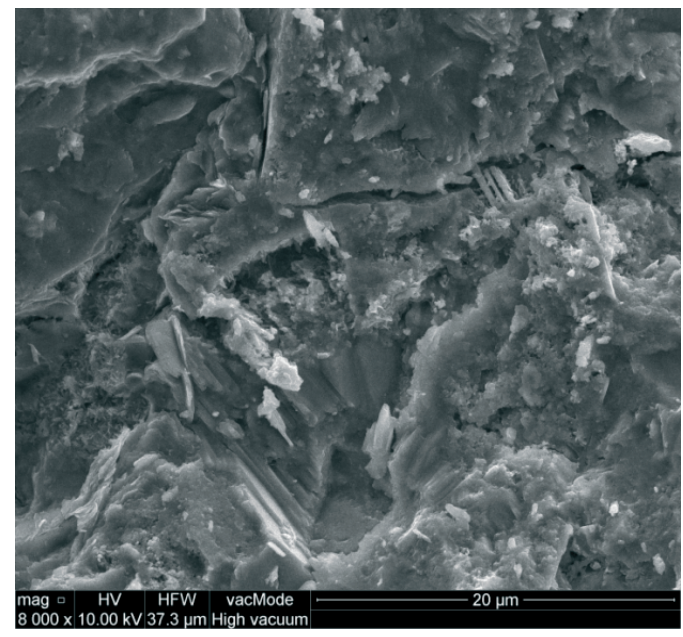

$\mathrm{Ca}$

b)

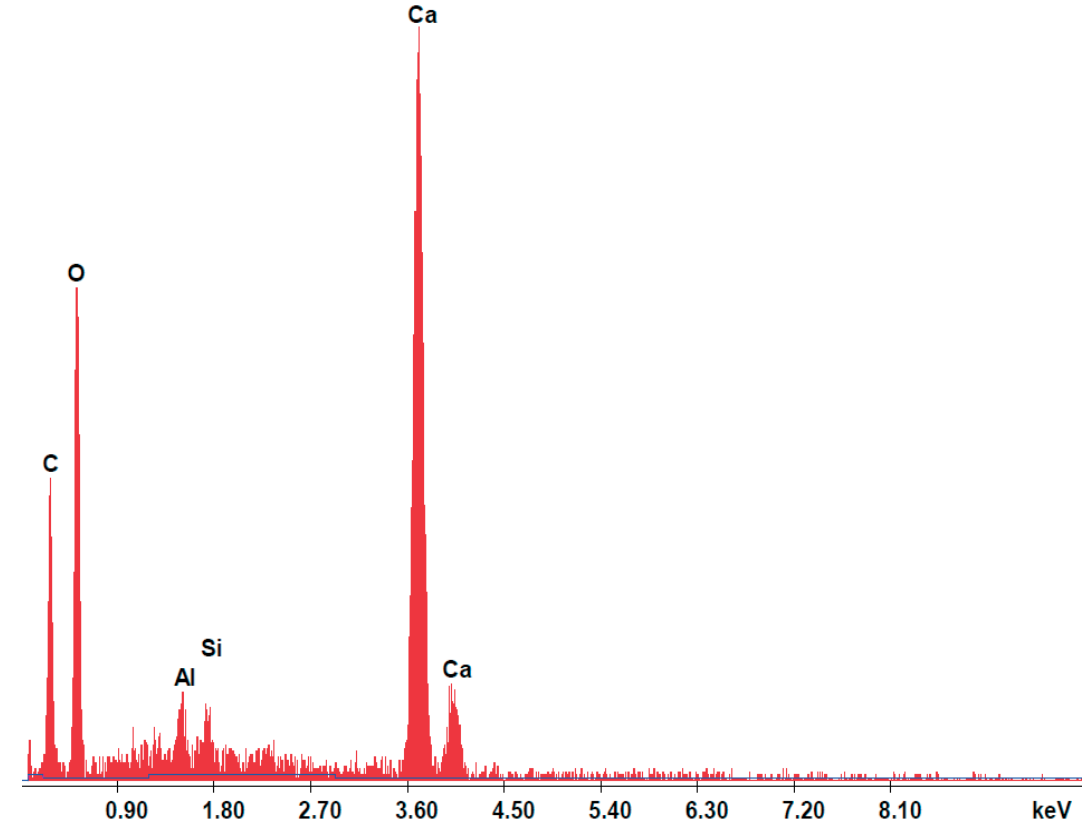

Fig. 5. SEM image (a) and EDX point (b) analysis of ordinary Portland cement stone after 28 days of hardening

It should be noted that fine crystalline ettringite, which is formed by hydration of Portland cement containing zeolite and chemical admixtures compared to hydrosulfoaluminate of conventional Portland cement, does not cause dangerous internal stresses. One of the characteristic peculiarities of the microstructure of Portland cement incorporating zeolite is a significant increase of metamikt component, confirming the effectiveness of the adsorption modification of binding system by admixtures of plasticizing action (Fig. 7).

Thus, the use of additives, such as zeolite and plasticizer makes it possible to create better hydration conditions, taking into consideration potential possibilities of the clinker and mineralogical components, compared with the Portland cement without additives. 


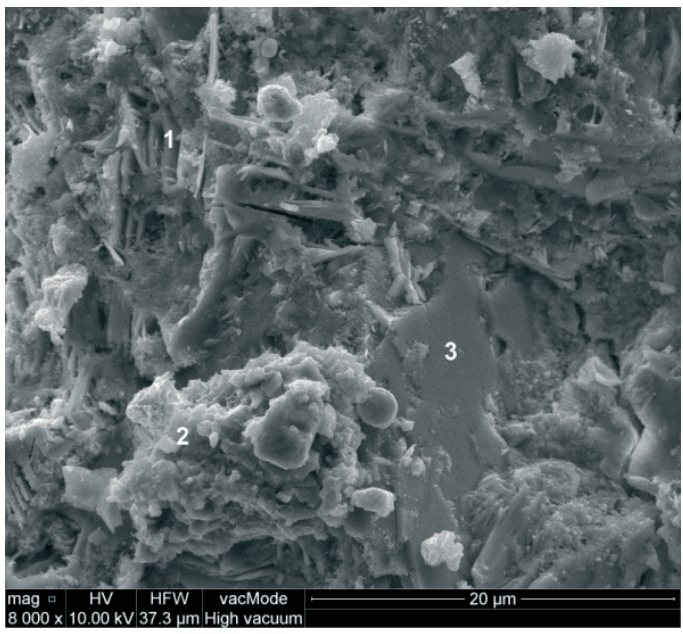

Spectrum 1

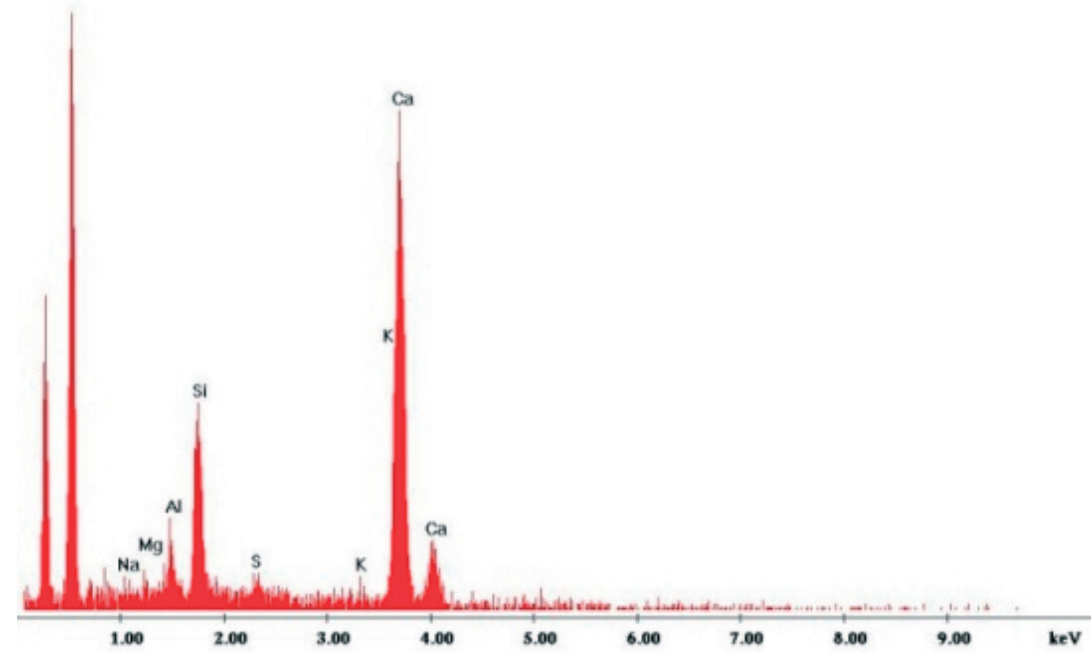

Spectrum 2

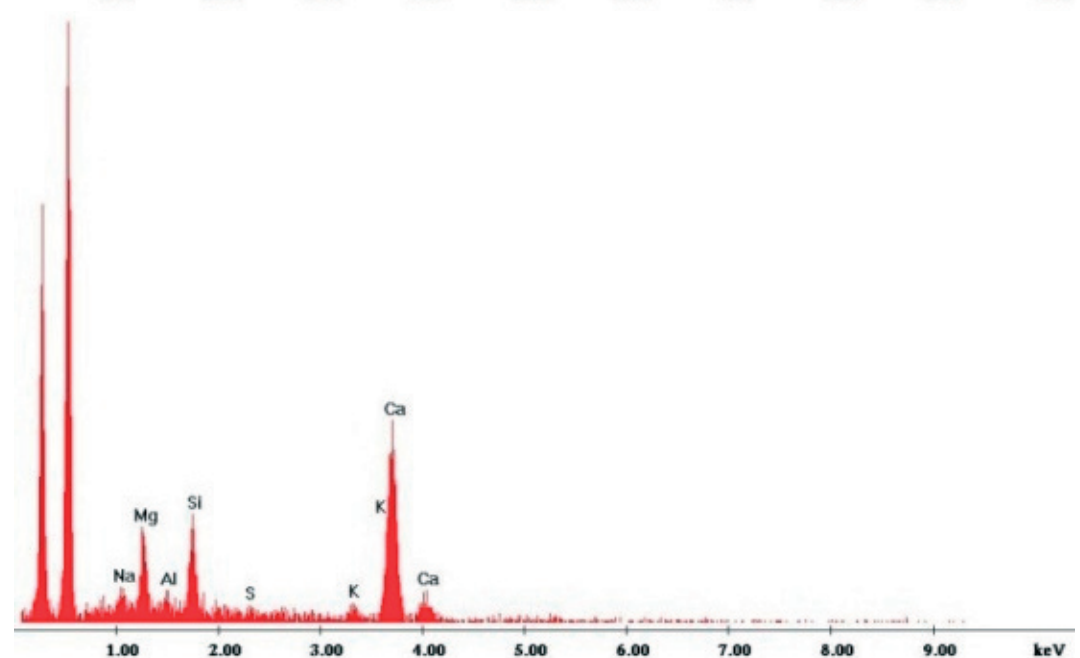




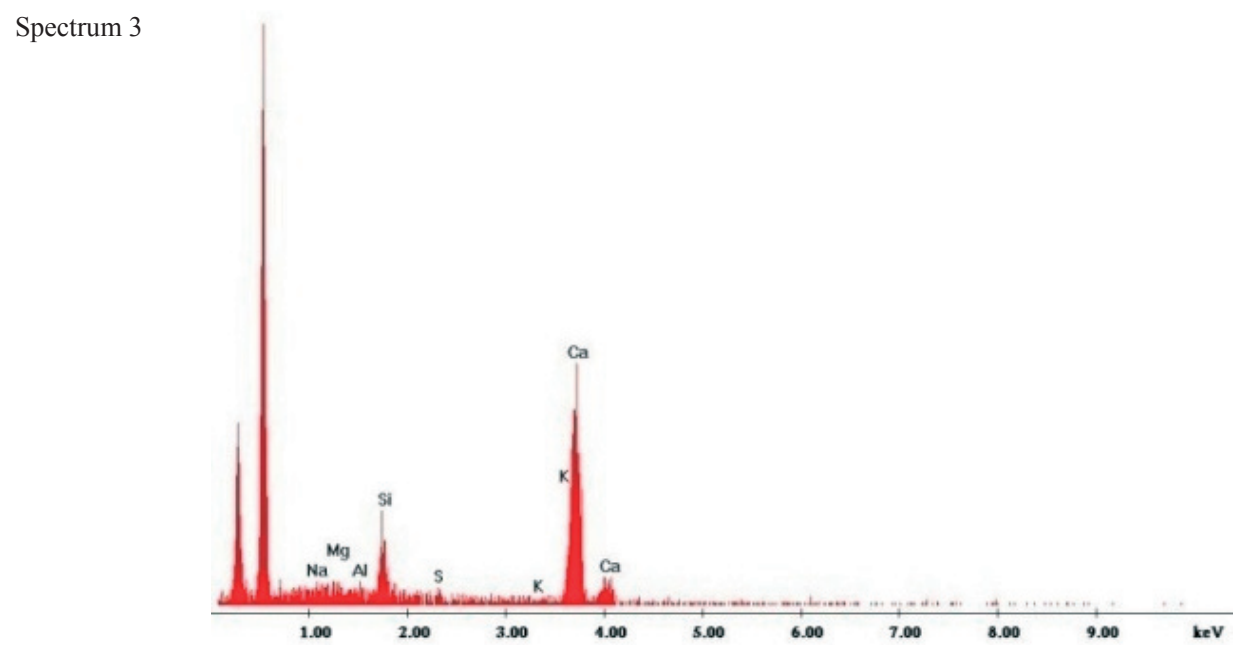

Fig. 6. SEM image and EDX point analysis of Portland cement paste containing $10 \mathrm{wt} . \%$ of zeolite after 28 days of hardening

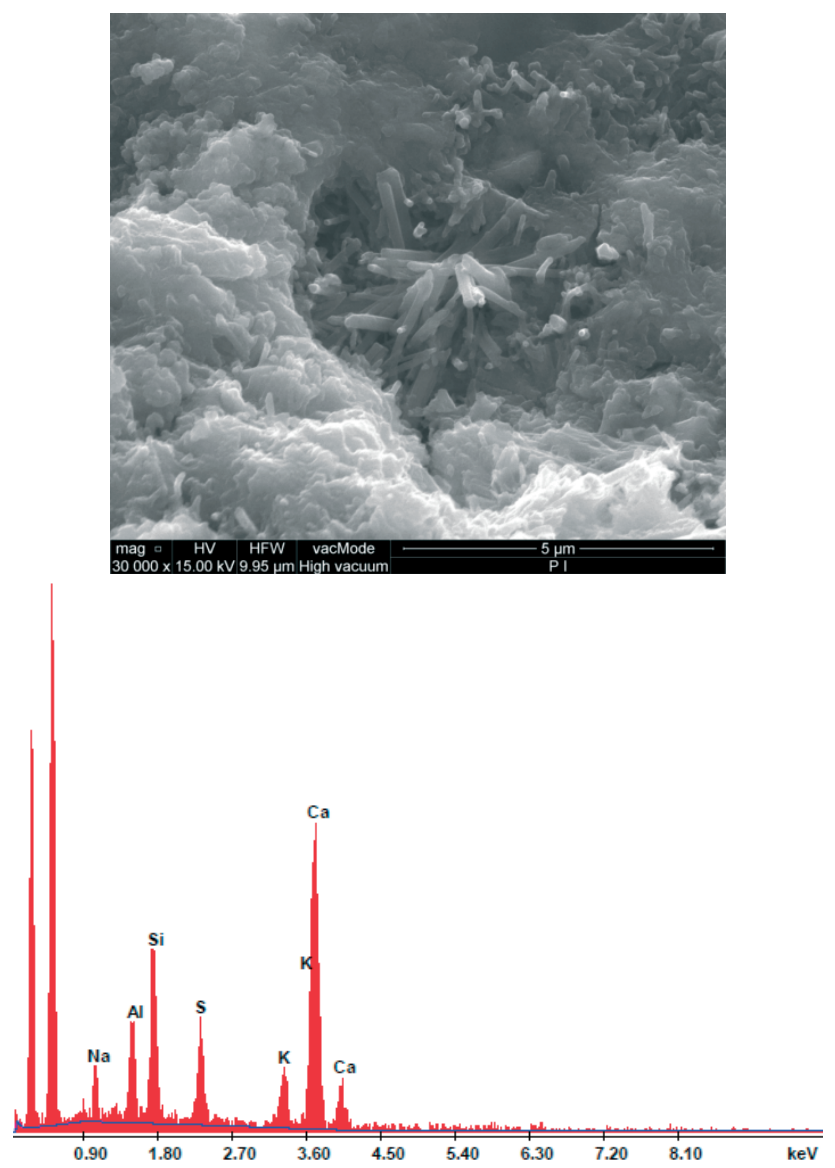

Fig. 7. SEM image and EDX point analysis of Portland cement paste containing $10 \mathrm{wt} . \%$ of zeolite and plasticizer after 28 days of hardening 


\section{Conclusion}

Regularities determining formulation of phase composition and microstructure of zeolite-containing cement compositions have been confirmed. This allows to adjust the parameters of cement system, creating the possibility of formation of hydrated phases which reveal binding properties in the mineral non-clinker part of Portland cement. The additional amount of hydrosilicate of the CSH type (B) provides strength synthesis of cement stone with high performance properties.

\section{Acknowledgement}

This research was financed by the Project No IPBU.01.01.00-06-570/11-00.

\section{References}

1 Snellings R., Mertens G., Cizer Ö., Elsen J. Early age hydration and pozzolanic reaction in natural zeolite blended cements: Reaction kinetics and products by in situ synchrotron X-ray powder diffraction. Cem. Concr. Res. 40 (2010) 1704-1713.

2 Kocak Y, Tasci E, Kaya U. The effect of using natural zeolite on the properties and hydration characteristics of blended cements. Constr Build Mater47 (2013) 720-727.

3 Najimi M, Sobhani J, Ahmadi B, Shekarchi M. An experimental study on durability properties of concrete containing zeolite as a highly reactive natural pozzolan. Constr Build Mater 35 (2012) 1023-1033.

4 Composite cements for energy-saving concrete technologies. w: M. Sanytsky, Kh. Sobol, T. Markiv, W. Bialczak // Praca zbiorowa Budownictwo o zoptymalizowanym potencjale energetycznym. Czestochowa, Polska, 2004, 373-377.

5 Sobol Kh., Blikharskyy Z., Petrovska N., Terlyha V. Analysis of structure formation peculiarities during hydration of oil-well cement with zeolitic tuff and metakaolin additives. Chemistry and chemical technology8(4) 2014 461-465.

6 Markiv T., Huniak O., Sobol Kh. Optimization of concrete composition with addition of zeolitic tuff. Journal of Lviv Polytechnic National University. Theory and practice of building 781 (2014) $116-121$.

7 Franus W. Characterization of X-type zeolite prepared from coal fly ash. Polish Journal of Environmental Studies 21 (2012) 337-343.

8 Bandura L., Panek R., Franus W. The use of clinoptilolite and synthetic zeolites for removal of petroleum substances. Journal of Lviv Polytechnic National University. Theory and practice of building 781 (2014) 9-17.

9 Bilek V., KerÅjner Z., Schmid P., Mosler T. The possibility of self-curing concrete. In: Dhir, Hewlett, Csetenyi, editors. Innovations and developments in concrete materials and construction. Proc. International Conference, Dundee, Scotland, UK. 9-11 September 2002, vol. 1. Thomas Telford, 2002. p. 51.

10 Zaichenko N.M. Internal curing and autogeneus shrinkage of high-strength concrete. Build Mater Constr J Ukrainian State Academy of Railway Transport 122 (2011) 236-244 [in Russian].

11 Bier T.A., Stolte B., Tokushige H., Kawakami M. Early shrinkage as influenced by water movement in mortars containing zeolites. Proc $9^{\text {th }}$ International Symposium on High Performance Concrete - Design, Verification \& Utilization. Energy Events Centre, Rotorua, New Zealand, 2011.

12 Sanytsky M., Sobol Kh., Markiv T. Modified composite cements. Lviv Polytechnic National University Publishing House, 2010, 132p [in Ukrainian].

13 Wagner G. Structures formation in silicate dispersions. K.: Naukova Dumka, 1989. 182p. [in Russian].

14 Sanytsky M., Markiv T., Kropyvnytska T., Krutc T. Modified composite cements and energetic aspects of waste utilization. $3^{\text {rd }}$ International Symposium Non-Tradition Cement and Concrete. Brno, 2008, 697-702. 
